\title{
Effect of Obesity on Static Strength and Explosive Power Among Egyptian Children Living In Egypt Versus Egyptian Children Living In Saudi Arabia
}

\author{
Mamdouh G. Haggag, $\mathrm{PhD}^{1}$, Mohamed T. ELdesoky, $\mathrm{PhD}^{2-3}$, \\ Enas A. Abd-Elaty, $\mathrm{PhD}^{4}$ \\ ${ }^{1}$ Lecturer, Department of Physical Therapy for Growth and Developmental Disorders in Children and its \\ Surgery, Faculty of Physical Therapy Cairo University, Egypt. \\ ${ }^{2}$ Assistant professor, Department of Physical Therapy, Faculty of Applied Medical Science, University of Tabuk, \\ Kingdom of Saudi Arabia. \\ ${ }^{3}$ Assistant professor, Department of Basic Science, Faculty of Physical Therapy, Cairo University, Egypt. \\ ${ }^{4}$ Lecturer of Orthopedic Physical Therapy, Department of Physical Therapy, Al-Matria Teaching Hospital, \\ Egypt
}

\begin{abstract}
Purposes: To determine the correlation between body mass index (BMI) and static strength (SS) and explosive power (EP), and to show the differences in all of them among Egyptian children living in Egypt and kingdom of Saudi Arabia (KSA). Subjects and procedures: 110 Egyptian children (10-15 years old) were selected from Egypt and KSA schools and classified according to BMI into obese, overweight, and normal group. Assessment of SS and EP have done using Hand Grip Strength and Standing Broad Jump tests respectively. Results: Significant negative correlations between BMI and EP and positive correlations between

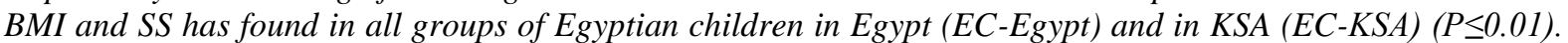
The EP scores were much higher in normal group compared to the overweight and obese children and the SS scores were much higher in obese and overweight groups compared to the normal children in both groups of

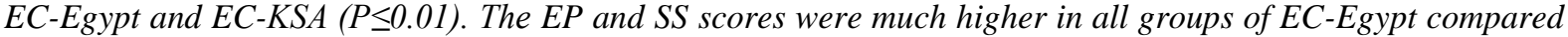
to the corresponding groups of $E C-K S A(P \leq 0.01)$ except between obese groups of EC-Egypt and EC-KSA have no differences $(P>0.05)$. Conclusion: The overweight and obese Egyptian children who live in Egypt and KSA have a decrease in physical performance in activities requiring forward acceleration and antigravity movement of the total body weight. In contrast, overweight and obese children showed greater static strength. Concentration on non-weight bearing activities during intervention or physical education session is recommended with obese children.
\end{abstract}

Keywords: Childhood Obesity, Egyptian Children, Hand Grip Strength, Physical Fitness, Standing Broad Jump

\section{Introduction}

One of the most serious public health defiance of the $21^{\text {st }}$ century is development of obesity during Childhood, as it has powerful relationship with other health complications as announced by the World Health Organization. ${ }^{[1,2]}$ In some developed countries in Middle East, high levels of children obesity have reported. ${ }^{[3]}$ The expansion of obesity in children may differ from city to another within the same country. ${ }^{[4]}$ In some developed countries, the prevalence of obesity in children developed 2 to 5 times in the last two decades of the 20th century. ${ }^{[5-8]}$ In Egypt, the propagation of overweight among children was 31.4\% and obesity was 9.3\% relatively to normal weighted children $56 \%$. ${ }^{[9]}$ Children obesity may cause metabolic disorders in adulthood. ${ }^{[10-}$ ${ }^{12]}$ In the previous study concerning a comparison between two national surveys 2001 and $2004{ }^{[13]}$, it was reported that the rates of children obesity were much higher in school age in Egypt that signal a very alarming trend, indicating the need to discover strategies to solve childhood obesity problem in Egypt. On the other side, the propagation of children obesity developed in Saudi Arabia (KSA) in the period from 1988 to 2005. ${ }^{[14]}$ Several studies reported that, the overall propagation of childhood obesity in KSA was $11.3 \%$ between children aged 5 to 18 years, was $12.1 \%$ in female children aged 13 to 18 years, and $13.8 \%$ in male of the same previous age range. ${ }^{[15,16]}$ Another study reported that, the propagation of children obesity in KSA among female children from 14 to 19 years was $14 \%$ and $24.1 \%$ in male with respect to geographical differences between the cities in KSA. ${ }^{[17]}$ In KSA, many factors as gender, the relative calmness of the surrounding environment, and luxury lifestyle including eating habits and physical inactivity may correlated with obesity in school-aged children. ${ }^{[18,19]}$ In Addition to the previous factors, unhealthy school canteen meals, fast food, and inadequate physical education sessions may develop the obesity rates in KSA. ${ }^{[4,20]}$ Obese children are at risk of musculoskeletal problems, and dynamic contraction of a group of muscles in a short period of time (i.e. the overall explosive 
power), which can lead to inclusion of obese children as dependent individuals in the society and more social problems to the children, and families, and shortened the lifespan. ${ }^{[21]}$

In the last 20 years, epidemiologists suggested that obesity might increase by either of excessive calorie intake or lack of physical fitness. ${ }^{[22,23]}$ The musculoskeletal component of physical fitness includes intact functioning of the musculoskeletal system. This requires that a group of muscles can generate force (i.e. muscle strength) to hold repeated contractions over time or to maintain maximum voluntary contraction for a prolonged period of time (i.e. muscular endurance) which represented in this study by hand grip strength test (HGS), and perform maximum, dynamic contraction of a group of muscles in a short period of time (i.e. the explosive power) which represented in this study by standing broad jump test (SBJ). ${ }^{[24-26]}$ European physical fitness test battery (Eurofit) was used by many researchers to assess the physical fitness ${ }^{[27]}$ including nine physical tests that measure different components of human fitness, one of the most important component is musculoskeletal component which includes the static strength that measured by HGS and explosive power that measured by SBJ. ${ }^{[28,29]}$ This Eurofit is commonly used in Europe and is reliable and valid instrument to measure physical fitness in children. ${ }^{[27]}$

So we conduct this study to show the differences in static strength (SS) and explosive power (EP) among Egyptian children who live in Egypt and who live in KSA and to determine the correlation between body mass index (BMI) and SS and EP. It was expected that there were differences between the Egyptian children who live in Egypt and who live in KSA due to the difference in the environmental conditions between the two countries. There is lack of literature in study of SS and EP among the researchers up to our Knowledge.

\subsection{SUBJECTS}

\section{Material And Methods}

In this study, 110 Egyptian children aged 10-15 years old were classified into two major groups; group one: 51 child randomly selected from Egyptian schools ( which concerning Egyptian children living in Egypt (EC-Egypt) and group two: 59 child randomly selected from KSA schools which concerning Egyptian children living in KSA (EC-KSA) and both groups were sub classified into three subgroups: normal weight (Egypt: 28 child, KSA: 33 child), overweight (Egypt: 13 child, KSA: 17 child), and obese (Egypt: 10 child, KSA: 9 child) according to international cut off points of Body Mass Index (BMI) for overweight and obese children between 2 and 18 year by sex. ${ }^{[30,31]}$ All children have informed of the experimental hazard and their parents signed a consent document and completed a questionnaire concerning the history of their children's health. The child has excluded if he had musculoskeletal impairments, hand or lower extremities injuries, and motor disorder. All the children can follow verbal commands included in the test. This study followed the principles of declaration of Helsinki.

\subsection{PROCEDURES}

The stadiometer (Seca 213, Weighing \& Instruments) has used to measure the child's height in meter to the nearest centimeter and the weighing scale (Seca 700, Weighing \& Instruments) has used to measure the child's weight in kilogram to the nearest gram. The children have evaluated with light clothes and without shoes. The BMI equation $=$ weight $/$ height $^{2}$ was used to calculate the BMI. Tape measurement has used to measure the distance in centimeter during SBJ. Digital hand dynamometer (Art. Nr.: 25327, Sport-Tec Physio \& Fitness, Germany) was used to measure the static strength of hand in kilogram to the nearest gram during HGS. The explosive power of lower limb and the static strength of hand have assessed by SBJ test and HGS test respectively. Committee of experts on sports research authorized the SBJ test and HGS test. ${ }^{[27]}$ Many researcher reported high validity HGS test and SBJ test to measure static strength of upper limb and explosive power of lower limb respectively in children and adolescents. ${ }^{[32-40]}$ Other researchers reported SBJ and HGS test as a reliable tests ${ }^{[28,29]}$ as interclass correlation coefficients of SBJ were $(\mathrm{ICC}=0.913)^{[41]}(\mathrm{ICC}=0.89)^{[42]}(\mathrm{ICC}=$ $0.88)^{[43]}$, and interclass correlation coefficients of HGS was $(\mathrm{ICC}=0.94)^{[42]}$, easy to perform , safe for children, understandable and very acceptable and by the children ${ }^{[41]}$, and non-invasive and requires limited facilities. ${ }^{[28,29]}$

All children toke preparatory session before the real test. During this session, anthropometric measurements were done included height, weight, and BMI with completing a questionnaire concerning the past history of child health and signing the consent form. The test started directly after the warming-up exercise. The SBJ test and HGS test have demonstrated first and all the children watched a video concerning the application of the SBJ and HGS tests to be familiar with them and to decrease the learning effect during the measurement session. The preparation session required to increase reliability, as Brewer et al ${ }^{[33]}$ mentioned that the pretest instructions and encouragement is important to improve the reliability of Eurofit battery test in children.

SBJ and HGS are two tests of the European physical fitness test battery (Eurofit) developed by Legér et $\mathrm{al}^{[29]}$ and authorized by committee of experts on sports research ${ }^{[27]}$ as they considered as a standardized test of explosive power of lower limb and the static strength of hand respectively. The SBJ test required simple equipment: measuring tape to measure distance jumped, non-slipped floor for takeoff, soft landed area. One 
starting takeoff line should be marked clearly on the ground. The child stood just behind the takeoff line with distance between his feet equal to the distance between his shoulders. The child started to jump with both feet together using bilateral arm swing and slight bending of both knees to provide forward drive. The child was encouraged to jump as far as possible and landing on both feet without falling backward. The child allowed two attempts and the longest distance was calculated. The HGS test required hand dynamometer. The handle of the dynamometer has adjusted to the child hand as the dynamometer base rested on the proximal part of metacarpals and the dynamometer handle rested on middle phalanges of the four fingers. The child held the dynamometer with the dominant hand keeping the elbow joint at $90^{\circ}$ flexion and the forearm in mid position between supination and pronation. The child has instructed to squeeze the dynamometer with maximum power and hold for 5 seconds. The child allowed two attempts and the maximum score has calculated in kilograms to the nearest gram.

\subsection{STATISTICAL ANALYSIS}

A statistical power Analysis suggested that sample sizes of 50 subjects per group were required to achieve $80 \%$ power. Data were first analyzed using Shapiro-Wilk test and Levene's test to test the normality of the data and the equality of variances, respectively. The differences in demographic characteristics (Age, weight, height, and BMI) in both groups of Egypt and KSA were assessed using unpaired t-tests and Chi-square test.

SBJ, and HGS were two variables that measured in this study. The mean and standard deviation have calculated for each variable in all groups, and the differences between mean values of each variable have calculated by using analysis of variance (ANOVA) for each variable in the three groups. The mean differences in-between the groups and between variables of EC-Egypt and the same variables of EC-KSA were measured using Fisher comparisons. The relationship between BMI and the standing broad jump and handgrip strength in all groups were evaluated using Pearson correlation ( $r$ ). All the data have analyzed using Minitab (Version 17) and the statistical significance was set as $(\mathrm{P} \leq 0.05)$.

\section{Results}

The overweight and obesity percentages in the study were $25.4 \%$ in OWG ${ }^{\text {Egypt }}, 19.6 \%$ in OG ${ }^{\text {Egypt }}$ (Fig. 1), $28.8 \%$ in $\mathrm{OWG}^{\mathrm{KSA}}$, and $15.3 \%$ in $\mathrm{OG}^{\mathrm{KSA}}$ (Fig. 2). The present study results reported highly significant negative correlations were found between the BMI and the EP in all groups of EC-Egypt and EC-KSA (P $\leq 0.01)$ except the obese groups of EC-Egypt and EC-KSA and the overweight group of EC-KSA the correlations were negatively significant $(\mathrm{P} \leq 0.05)$. Highly significant positive correlations were found between the BMI and the $\mathrm{SS}$ in all groups of EC-Egypt and EC-KSA $(\mathrm{P} \leq 0.01)$ except the obese group of EC-KSA and the overweight group of EC-Egypt the correlations were positively significant $(\mathrm{P} \leq 0.05)$ (Table 1). The ANOVA reported highly significant different scores of EP and SS between the three groups of EC-Egypt and EC-KSA (EP Egypt: $\mathrm{f}$ $=160.56, \mathrm{P} \leq 0.01)\left(\mathrm{EP}^{\mathrm{KSA}}: \mathrm{f}=54.29, \mathrm{P} \leq 0.01\right)\left(\mathrm{SS}^{\mathrm{Egypt}}: \mathrm{f}=15.27, \mathrm{P} \leq 0.01\right)\left(\mathrm{SS}^{\mathrm{KSA}}: \mathrm{f}=33.59, \mathrm{P} \leq 0.01\right)(\mathrm{Table}$ $2)$. The statistical results showed non- significant differences between ages and heights in the all groups of ECEgypt and EC-KSA (all P> 0.05) (Table 2, Fig. 3). Fisher comparisons showed that the score of EP is much higher in normal group of children compared to the overweight and obese children in both groups of EC-Egypt and EC-KSA (all P $\leq 0.01$ ) and showed that the score of SS is much higher in obese and overweight groups of children compared to the normal children in both groups of EC-Egypt and EC-KSA (all P $\leq 0.01$ ) except between obese and overweight groups, the scores have no significant differences in both groups of EC-Egypt and EC-KSA (all P> 0.05) (Table 3, Fig. 3). The statistical analysis showed that the scores of EP and SS were much higher in the groups of EC-Egypt compared to the groups of EC-KSA (all P $\leq 0.01$ ) except between the obese groups of EC-Egypt and EC-KSA have no differences ( $\mathrm{P}>0.05)$ (Table 4, Fig. 3).

TABLE 1 Summary of correlations between Explosive Power of lower limb, Static Strength of hand, and body mass index in Egyptian children living in Egypt and in Saudi Arabia.

\begin{tabular}{|c|c|c|c|c|c|c|c|c|c|}
\hline & \multicolumn{3}{|c|}{ NWG } & \multicolumn{3}{|c|}{ OWG } & \multicolumn{3}{|c|}{ OG } \\
\hline & $n$ & $r$ & $\boldsymbol{P}$ & $N$ & $r$ & $p$ & $n$ & $r$ & $p$ \\
\hline EP EGYPT & 28 & -0.49 & $0.009 *$ & 13 & -0.68 & $0.01 * *$ & 10 & -0.68 & $0.03 * *$ \\
\hline SS $^{\text {EGYPT }}$ & 20 & 0.78 & $0.00^{*}$ & 15 & 0.62 & $0.02 * *$ & 10 & 0.76 & $0.01 * *$ \\
\hline EP ${ }^{\text {KSA }}$ & & -0.50 & $0.003^{*}$ & & -0.56 & $0.02 * *$ & & -0.71 & $0.03 * *$ \\
\hline SS $^{\text {KSA }}$ & 33 & 0.48 & $0.005^{*}$ & 17 & 0.60 & $0.01 * *$ & 9 & 0.74 & $0.02 * *$ \\
\hline
\end{tabular}

\begin{tabular}{|l|l|l|}
\hline EP = Explosive power of lower limb & OWG = Over weight group & $p=\mathrm{P}-$ value; \\
SS = Static strength of hand & OG = Obese group & $*=\mathrm{P} \leq 0.01 ;$ \\
KSA = Kingdom of Saudi Arabia & $n \quad$ = Group number & $* *=\mathrm{P} \leq 0.05$. \\
NWG = Normal weight group & $r \quad=$ Pearson correlation & \\
\hline
\end{tabular}


Effect of Obesity on Static Strength and Explosive Power Among Egyptian Children Living In Egypt ..

TABLE 2 Summary of mean values and analysis of variance of age, height, weight, body mass index, Explosive Power of lower limb, and Static Strength of hand in Egyptian children living in Egypt and in Saudi Arabia.

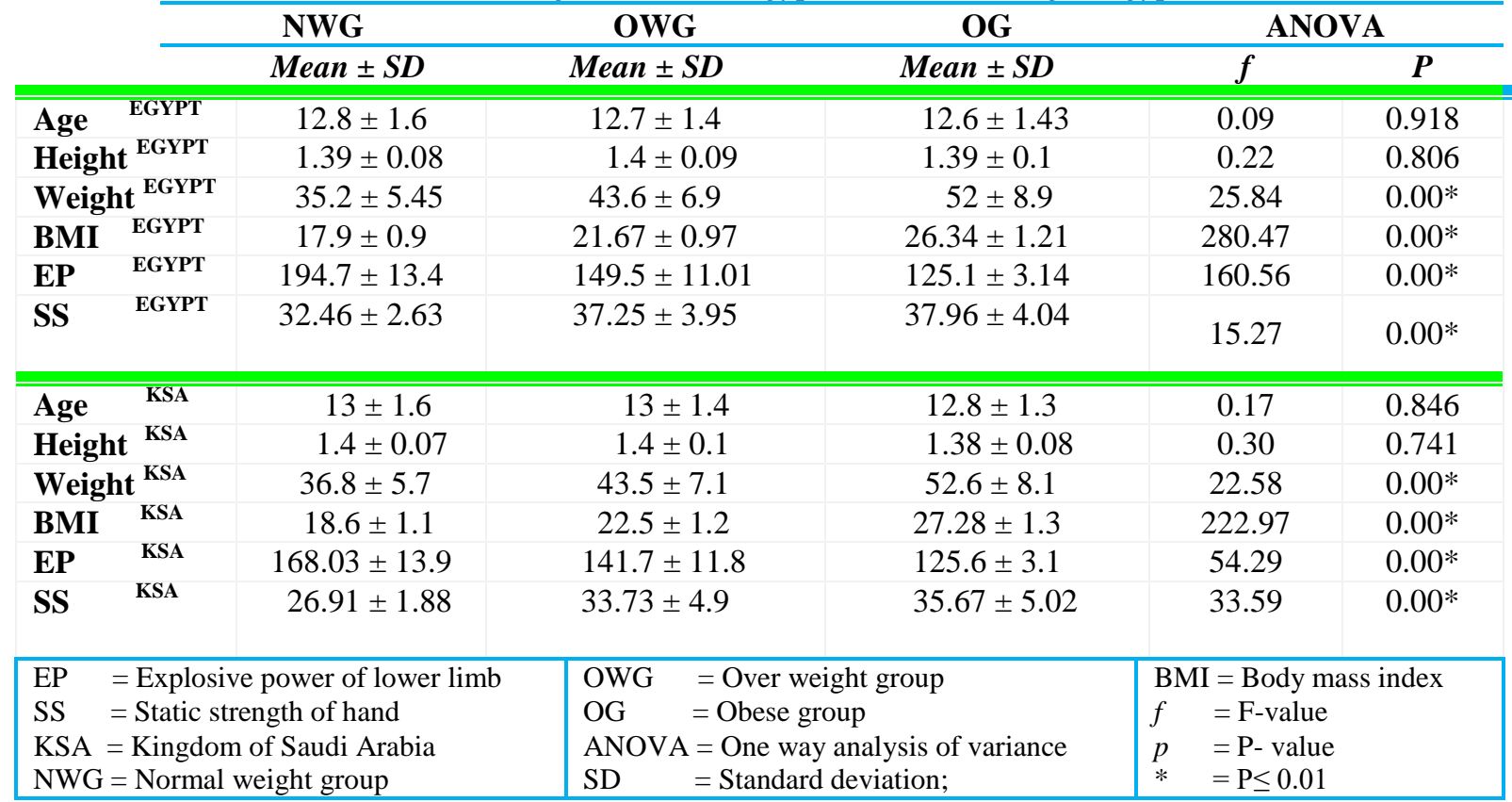

TABLE 3 Summary of Fisher Pairwise comparisons of age, height, weight, body mass index, Explosive Power of lower limb, and Static Strength of hand among the three groups of Egyptian children living in Egypt and in Saudi Arabia.

\begin{tabular}{|c|c|c|c|c|c|c|c|c|c|}
\hline & \multicolumn{3}{|c|}{ NWG vs. OWG } & \multicolumn{3}{|c|}{ NWG vs. OG } & \multicolumn{3}{|c|}{ OWG vs. OG } \\
\hline & $M D$ & $t$ & $\boldsymbol{P}$ & $M D$ & $t$ & $P$ & $M D$ & $t$ & $\boldsymbol{P}$ \\
\hline Age $\quad$ EGYPT & -0.15 & -0.29 & 0.8 & -0.2 & -0.36 & 0.7 & -0.05 & -0.08 & 0.93 \\
\hline Height EGYPT & 0.02 & 0.66 & 0.5 & 0.01 & 0.15 & 0.7 & -0.01 & -0.39 & 0.7 \\
\hline Weight ${ }^{\text {EGYPT }}$ & 8.4 & 3.81 & $0.00 *$ & 16.9 & 6.94 & $0.00 *$ & 8.4 & 3.03 & $0.00 *$ \\
\hline BMI EGYPT & 3.7 & 11.3 & $0.00 *$ & 8.4 & 23.2 & $0.00 *$ & 4.8 & 11.3 & $0.00 *$ \\
\hline EP $\quad$ EGYPT & -45.3 & -11.7 & $0.00 *$ & -69.6 & -16.4 & $0.00 *$ & -24.4 & -5.02 & $0.00 *$ \\
\hline EGYPT & 4.8 & 4.33 & $0.00 *$ & 5.5 & 4.5 & $0.00 *$ & 0.7 & 0.52 & 0.609 \\
\hline Age KSA & 0.04 & 0.1 & 0.92 & -0.3 & -0.52 & 0.60 & -0.34 & -0.55 & 0.59 \\
\hline Height ${ }^{\text {KSA }}$ & -0.02 & -0.65 & 0.52 & -0.02 & -0.58 & 0.56 & -0.002 & -0.06 & 0.95 \\
\hline Weight $^{\text {KSA }}$ & 6.77 & 3.5 & $0.00 *$ & 15.8 & 6.47 & $0.00 *$ & 9 & 3.37 & $0.00 *$ \\
\hline BMI KSA & 3.9 & 11.5 & $0.00 *$ & 8.7 & 20.2 & $0.00 *$ & 4.8 & 10.1 & $0.00 *$ \\
\hline EP KSA & -26.3 & -7.19 & $0.00 *$ & -42.5 & -9.2 & $0.00 *$ & -16.2 & -3.19 & $0.00 *$ \\
\hline SS KSA & 6.8 & 6.47 & $0.00 *$ & 8.8 & 6.6 & $0.00 *$ & 1.94 & 1.33 & 0.189 \\
\hline $\begin{array}{l}\text { EP = Explosi } \\
\text { SS = Static stre } \\
\text { KSA = Kingdor } \\
\text { NWG = normal }\end{array}$ & $\begin{array}{l}\text { ower of } 1 \\
\text { h of hand } \\
\text { Saudi A } \\
\text { ght groul }\end{array}$ & $\begin{array}{l}\text { er limb } \\
\text { ia }\end{array}$ & $\begin{array}{l}\text { OWG } \\
\text { OG } \\
t\end{array}$ & $\begin{array}{l}\text { er weigl } \\
\text { ese grou } \\
\text { value }\end{array}$ & & & $\begin{array}{l}\text { MD } \\
p \\
*\end{array}$ & $\begin{array}{l}\text { mean di } \\
\mathrm{P}-\text { value } \\
\mathrm{P} \leq 0.01\end{array}$ & \\
\hline
\end{tabular}

TABLE 4 Summary of Fisher Pairwise comparisons between age, height, weight, body mass index, Explosive Power of lower limb, and Static Strength of hand variables of Egyptian children living in Egypt and the same variables of Egyptian children living in Saudi Arabia.

\begin{tabular}{|c|c|c|c|c|c|c|c|c|c|}
\hline & \multicolumn{3}{|c|}{ NWG ${ }^{\text {EGY vs. KSA }}$} & \multicolumn{3}{|c|}{ OWG ${ }^{\text {EGY vs. KSA }}$} & \multicolumn{3}{|c|}{$\mathrm{OG}^{\mathrm{EGY} \text { vs. KSA }}$} \\
\hline & $M D$ & $t$ & $\boldsymbol{P}$ & $M D$ & $t$ & $\boldsymbol{P}$ & $M D$ & $t$ & $\boldsymbol{P}$ \\
\hline Age & 0.21 & 0.18 & 0.86 & 0.4 & 0.25 & 0.81 & 0.12 & 0.08 & 0.94 \\
\hline Height & 0.01 & 0.01 & 0.99 & -0.03 & -0.02 & 0.98 & -0.01 & -0.01 & 0.99 \\
\hline Weight & 1.65 & 1.41 & 0.16 & -0.01 & -0.01 & 0.99 & 0.58 & 0.37 & 0.71 \\
\hline BMI & 0.64 & 0.54 & 0.59 & 0.85 & 0.52 & 0.61 & 0.94 & 0.60 & 0.55 \\
\hline
\end{tabular}


Effect of Obesity on Static Strength and Explosive Power Among Egyptian Children Living In Egypt ..

EP
SS
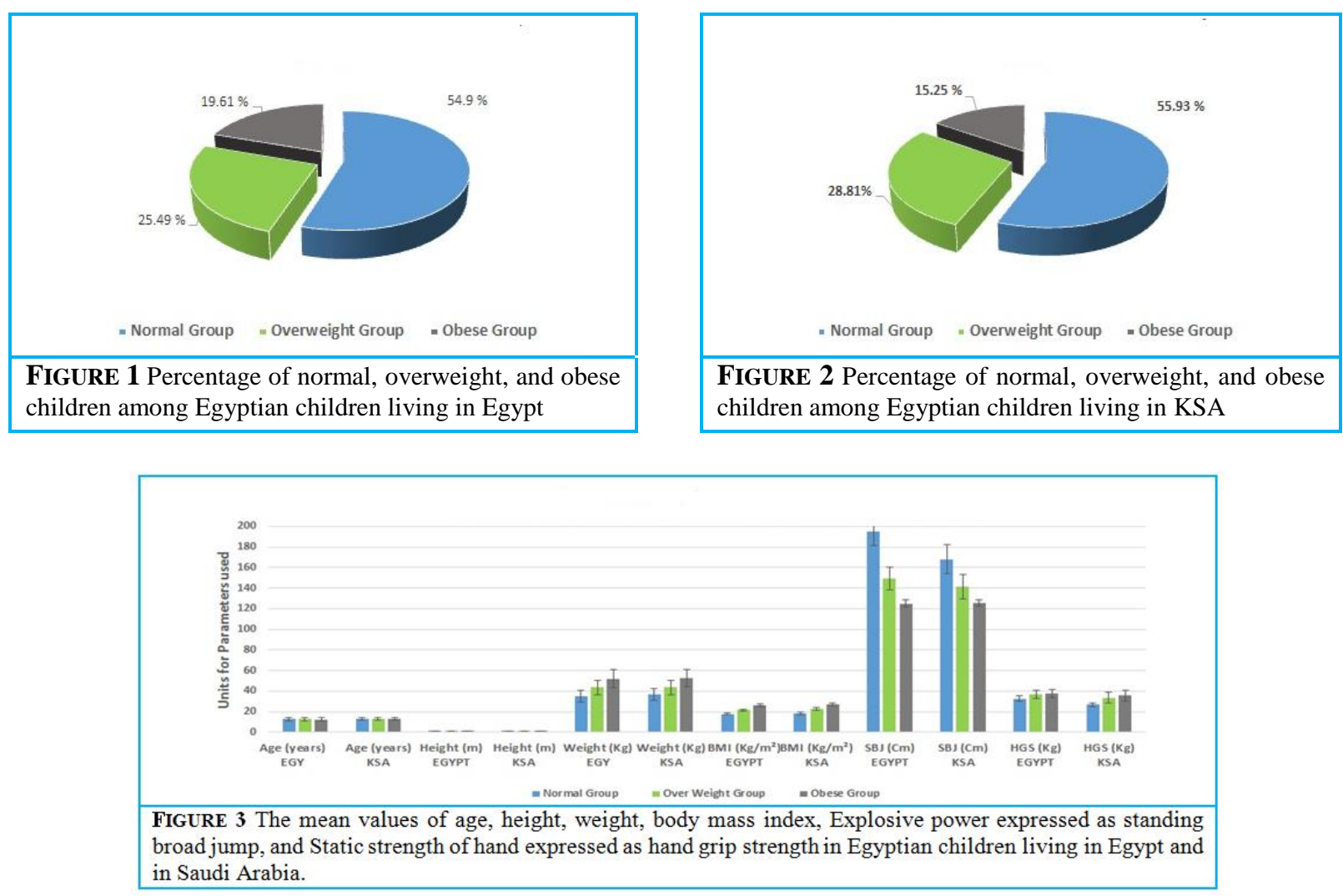

\section{Discussion}

The aim of this study were to determine the correlation between body mass index (BMI) and static strength (SS) and explosive power (EP), and to show the SS and EP differences in Egyptian children living in Egypt and kingdom of Saudi Arabia (KSA). The overweight and obesity percentages in the our study were $25.4 \%$ in OWG ${ }^{\text {Egypt }}, 19.6 \%$ in OG ${ }^{\text {Egypt }}, 28.8 \%$ in $\mathrm{OWG}^{\mathrm{KSA}}$, and $15.3 \%$ in $\mathrm{OG}^{\mathrm{KSA}}$. These percentages were nearly similar to those reported by Taru et al ${ }^{[9]}$ that the overweight children percentage in Egypt was $31.41 \%$. Many previous researchers used the same percentage ${ }^{[44-47]}$ among schoolchildren from Greece. Our results reported significant negative correlations between BMI and EP and positive correlations between BMI and SS were present in all groups of EC-Egypt and EC-KSA $(\mathrm{P} \leq 0.01)$. The EP scores were much higher in normal children compared to the overweight and obese children and the SS scores were much higher in obese and overweight children compared to the normal one in EC-Egypt and EC-KSA $(\mathrm{P} \leq 0.01)$. These results came in agreement with other studies that reported a relation between components of physical fitness and BMI in children. ${ }^{[48-55]}$ It has reported that overweight and obese children showed a lower explosive power and higher static strength than normal children did. ${ }^{[49,56-58]}$ Several defenses may clarify the deterioration of explosive power in obese and overweight children. First, low level of care about the physical education programs in the schools especially the activities required antigravity movement or those required forward acceleration as it is important to improve the physical fitness. A previous study reported that the children spent more time in physical education program had higher physical fitness than those who spent less time. ${ }^{[59-60]}$ Second, Sedentary behaviors may also cause deterioration of explosive power in obese and overweight children, as Mitchell et al [61] reported that sedentary behaviors is negatively related to fatness among children. It has reported by Gordonlarsen et al ${ }^{[63]}$ that sedentary life style increase from childhood to adolescence. ${ }^{[62]}$ Some factors may cause coronary heart disease as low explosive power, childhood fatness, and sedentary behaviors. ${ }^{[64]}$ This explained by the fact that low antigravity activity levels decrease the oxidation capacity of muscular fat, which in turn reduce the tolerance of fat intake and develop body fatness. ${ }^{[65-66]}$ Third defense, Fear of poor 
performance may explain the negative relationship between EP and BMI, as reported previously that obese children might refuse to share in physical exercise because of apprehension of stigmatization and bad performance that develop overweight/obese status. ${ }^{[67]}$ This may highlight the need for psychological support to encourage participation of obese children in activities. Another defense that may clarify the progression of static strength in obese and overweight children is pubertal stage of the children. Kaplowitz et al ${ }^{\text {[68] }}$ reported that obese children and adolescents being advance in maturation and the variations in performance on the fitness tests between obese and normal children affected by variations in maturation. Biological maturation is positively correlated with static strength and negatively correlated with performances in activities required the children act against their own body mass. ${ }^{[69]}$

In our study, the EP and SS scores were much higher in all groups of EC-Egypt compared to the corresponding groups of EC-KSA $(\mathrm{P} \leq 0.01)$ except between obese groups of EC-Egypt and EC-KSA have no differences $(\mathrm{P}>0.05)$. There was no explanation for that exception of the results of obese groups of EC-Egypt and EC-KSA and it may be a point of interest to be studied in the future. The other groups result can be explained as the Egyptian children sample living in KSA may spent enough time in KSA, so the environmental, economic, and social effects were sufficient to change the EP and SS scores. The effects that include the sedentary behavior, socioeconomic status, family, and local society may affect the physical fitness. ${ }^{[22]}$ It has reported previously that the socioeconomic status of Saudi children improved after discovery of petrol in KSA. ${ }^{[70]}$ As a result of changes in socioeconomic status, most Saudi children are playing less in open fields, playing video games, and watching television for prolonged time. ${ }^{[4,18]}$ From the previous reports, the Egyptian children who have spent a lot of time living in KSA may upgrade their socioeconomic status as Saudi children and act like them in sedentary behaviors.

\section{Conclusion}

This study concluded that BMI correlate negatively with EP and positively with SS, the normal and overweighed EC-Egypt have much higher static strength and explosive power than EC-KSA with exception of obese children, and finally concluded that as the weight increased, the static strength increased and the explosive power decreased. This study demonstrated that overweight and obese Egyptian children living in Egypt and KSA have decreased physical performance in activities requiring forward acceleration and antigravity movement of the total body weight. In contrast, overweight and obese children showed greater static strength. Based on these research results and previous reports in the literature, we recommend decrease the intensity of weight-bearing activities at the beginning of an intervention or physical education session for obese children and high concentration on non-weight-bearing activities especially those relying on static strength. Weight control exercise and physical fitness programs are needed to increase the effectiveness of the therapeutic and physical education programs.

The present study had one limitation that may interfere with the clear explanations of the difference between EC-Egypt and EC-KSA in the EP and SS scores. The pubertal stage of the children has not assessed in this study. As maturity may affect the muscle development, the mature children can perform better in static and explosive power than immature children. ${ }^{[71]}$ Self-maturity questionnaires could be used as a valid tool to assess the maturity in the future studies. ${ }^{[72,73]}$ Two points powered the study. First, the study was the first to assess the effect of BMI on static and explosive power among Egyptian children. Second, the study was the first to compare the physical fitness between two groups of children living in different Arabian countries.

\section{Acknowledgement}

The authors would like to thank all parents and their children who enrolled in this study for their participation and all schools administrators for their help.

\section{Conflict Of Interest}

No potential conflict of interests relevant to this study.

\section{References}

[1] Park, M. H., C. Falconer, R. M. Viner, and S. Kinra. "The Impact of Childhood Obesity on Morbidity and Mortality in Adulthood: A Systematic Review." Obesity Reviews 13.11 (2012): 985-1000.

[2] Reilly, J. J., and J. Kelly. "Long-term Impact of Overweight and Obesity in Childhood and Adolescence on Morbidity and Premature Mortality in Adulthood: Systematic Review." International Journal of Obesity 35.7 (2010): 891-98.

[3] Ulijaszek, Stanley J. "Obesity: Preventing and Managing the Global Epidemic. Report of a WHO Consultation. WHO Technical Report Series 894. Pp. 100-142.

[4] Musaiger, Abdulrahman O. "Overweight and Obesity in Eastern Mediterranean Region: Prevalence and Possible Causes." Journal of Obesity 2011 (2011): 1-17.

[5] Ulijaszek, Stanley J. "Obesity: Preventing and Managing the Global Epidemic. Report of a WHO Consultation. WHO Technical Report Series 894. Pp. 252. (World Health Organization, Geneva, 2000.) SFr 56.00, ISBN 92-4-120894-5, Paperback." Journal of Biosocial Science 35.4 (2003): 624-25. 
[6] Ogden, Cynthia L., Margaret D. Carroll, Lester R. Curtin, Margaret A. Mcdowell, Carolyn J. Tabak, and Katherine M. Flegal. "Prevalence of Overweight and Obesity in the United States, 1999-2004." Jama 295.13 (2006): 1549.

[7] Seidell, Jc. "Obesity: A Growing Problem." Acta Paediatrica 88.S428 (1999): 46-50.

[8] Lissau, I. "Overweight and Obesity Epidemic among Children. Answer from European Countries." International Journal of Obesity 28 (2004):S10- 5.

[9] Manyanga, Taru, Hesham El-Sayed, David Teye Doku, and Jason R. Randall. "The Prevalence of Underweight, Overweight, Obesity and Associated Risk Factors among School-going Adolescents in Seven African Countries." BMC Public Health 14.1 (2014): 887

[10] Juonala, Markus, Costan G. Magnussen, Gerald S. Berenson, Alison Venn, Trudy L. Burns, Matthew A. Sabin, Sathanur R. Srinivasan, Stephen R. Daniels, Patricia H. Davis, Wei Chen, Cong Sun, Michael Cheung, Jorma S.a. Viikari, Terence Dwyer, and Olli T. Raitakari. "Childhood Adiposity, Adult Adiposity, and Cardiovascular Risk Factors." New England Journal of Medicine 365.20 (2011): 1876-885.

[11] Morrison, J. A., L. A. Friedman, and C. Gray-Mcguire. "Metabolic Syndrome in Childhood Predicts Adult Cardiovascular Disease 25 Years Later: The Princeton Lipid Research Clinics Follow-up Study." Pediatrics 120.2 (2007): 340-45.

[12] Bibbins-Domingo, Kirsten, Pamela Coxson, Mark J. Pletcher, James Lightwood, and Lee Goldman. "Adolescent Overweight and Future Adult Coronary Heart Disease." New England Journal of Medicine 357.23 (2007): 2371-379.

[13] Shaheen, F.M., Hathout, M. and Tawfik, A.A. National Survey of Obesity in Egypt. Final report, National Nutrition Institute, 2004; Egypt.

[14] World Health Organization. Country Cooperation Strategy for WHO and Saudi Arabia 2006-2011, Regional Office for the Eastern Mediterranean, Cairo; 2006. p. 8-45.

[15] Musaiger, Abdulrahman O. "Overweight and Obesity in Eastern Mediterranean Region: Prevalence and Possible Causes." Journal of Obesity 2011 (2011): 1-17.

[16] Mouzan, Mohammadi El, Peterj Foster, Abdullahs Al Herbish, Abdullaha Al Salloum, Ahmada Al Omer, Mansourm Qurachi, and Tatjana Kecojevic. "Prevalence of Overweight and Obesity in Saudi Children and Adolescents." Annals of Saudi Medicine 30.3 (2010): 203-208

[17] Al-Hazzaa, Hazzaa M., Nada A. Abahussain, Hana I. Al-Sobayel, Dina M. Qahwaji, Nouf A. Alsulaiman, and Abdulrahman O. Musaiger. "Prevalence of Overweight, Obesity, and Abdominal Obesity among Urban Saudi Adolescents: Gender and Regional Variations." Journal of Health, Population, and Nutrition. International Centre for Diarrhoeal Disease Research, Bangladesh, 2014.

[18] Khalid, Mohammed El-Habib. "Is High-Altitude Environment a Risk Factor for Childhood Overweight and Obesity in Saudi Arabia?" Wilderness and Environmental Medicine 19.3 (2008): 157- 163.

[19] Al-Rukban M. Obesity among Saudi male adolescents in Riyadh, Saudi Arabia. Saudi Med J 2003;24:27-33.

[20] Osman AK, Al-Nozha MM. Risk factors of coronary artery disease in different regions of Saudi Arabia. East Mediterr Health J $2000 ; 6: 465-74$.

[21] Dugan, Sheila A. "Exercise for Preventing Childhood Obesity." Physical Medicine and Rehabilitation Clinics of North America 19.2 (2008): 205-16.

[22] Lobstein, T., L. Baur, and R. Uauy. "Obesity in Children and Young People: A Crisis in Public Health." Obesity Reviews 5.S1 (2004): 4-85.

[23] Roberts, Sb. "Regulation of Energy Intake in Relation to Metabolic State and Nutritional Status." European Journal of Clinical Nutrition 54 (2000): 71:154-6.

[24] Ruiz, J.R., Castro-Piñero, J., Artero, E.G., Ortega, F.B., Sjöström, M., Suni, J., et al. "Predictive validity of health-related fitness in youth: a systematic review." British Journal of Sports Medicine, 43, (2009). (12), 909-923.

[25] Ruiz JR, Castro-Piñero J, España-Romero V, Artero EG, Ortega FB, Cuenca MM, et al. "Field-based fitness assessment in young people: The ALPHA health-related fitness test battery for children and adolescents." Br J Sports Med. 45(6), (2011):518-24.

[26] Cvejić D, Pejović T, Ostojić S (2013)"Assessment of physical fitness in children and adolescents." Phys Educ Sport 11(2):135-45.

[27] Adam C, Klissouras V, Ravasollo M (1988) Eurofit: Handbook for the Eurofit Tests of Physical Fitness: Rome: Council of Europe. Committee for the Development of Sport.

[28] Faude O, Nowacki PE, Urhausen A "Vergleich ausgewaehlter (unblutiger) Testverfahren zur Bestimmung der kardiopulmonalen Ausdauer bei Schulkindern (Comparison of non-invasive tests to assess cardio-respiratory fitness in school children)". Dtsch Z Sportmed 55(9), (2004):232-236.

[29] Léger, L. A., D. Mercier, C. Gadoury, and J. Lambert. "The Multistage 20 Metre Shuttle Run Test for Aerobic Fitness." Journal of Sports Sciences 6.2 (1988): 93-101.

[30] Cole, T. J. "Establishing a Standard Definition for Child Overweight and Obesity Worldwide: International Survey." Bmj 320.7244 (2000): 1240 .

[31] Cole, T. J., K. M. Flegal, D. Nicholls, and A. A. Jackson. "Body Mass Index Cut Offs to Define Thinness in Children and Adolescents: International Survey." Bmj 335.7612 (2007): 194-7.

[32] Léger, Luc A., and J. Lambert. "A Maximal Multistage 20-m Shuttle Run Test to Predict VO2max" European Journal of Applied Physiology and Occupational Physiology 49.1 (1982): 1-12.

[33] Léger, L.A., Lambert, J., Goulet, A., Rowan, C., \& Dinelle, Y. (1984). Capacité aérobie des Québécois de 6 à 17 ans - test navette de 20 mètres avec paliers de 1 minute. Canadian Journal of Applied Sport Sciences, 9(2), 64-69.

[34] Ramsbottom, R., J. Brewer, and C. Williams. "A Progressive Shuttle Run Test to Estimate Maximal Oxygen Uptake." British Journal of Sports Medicine 22.4 (1988): 141-44.

[35] Brewer, John, Roger Ramsbottom, and Clyde Williams. Multistage Fitness Test: A Progressive Shuttle-run Test for the Prediction of Maximum Oxygen Uptake. Beckett Park, Leeds: National Coaching Foundation, 1988.

[36] Leger, L. and Gadoury, C, (1989) 'Validity of the 20m shuttle run test with 1 minute stages to predict VO2max in adults. Canadian Journal of Sport Science, 14:1 21-26.

[37] Riddoch, Chris. Northern Ireland Health and Fitness Survey 1989: The Fitness, Physical Activity, Attitudes and Lifestyles of Northern Ireland Post-primary Schoolchildren: A Report. Belfast: Division of Physical and Health Education, Queen's U Belfast, 1990 .

[38] Australian Sports Commission (1999). 20m Shuttle Run Test: A Progressive Shuttle Run Test for measuring Aerobic Fitness. Belconnen (ACT): Australian Coaching Council.

[39] Tomkinson, Grant R., Luc A. Léger, Tim S. Olds, and Georges Cazorla. "Secular Trends in the Performance of Children and Adolescents (1980-2000)." Sports Medicine 33.4 (2003): 285-300. 
[40] Olds, Tim, Grant Tomkinson, Luc Léger, and Georges Cazorla. "Worldwide Variation in the Performance of Children and Adolescents: An Analysis of 109 Studies of the 20-m Shuttle Run Test in 37 Countries." Journal of Sports Sciences 24.10 (2006): 1025-038.

[41] Rodrigues-Bezerra, Diogo, Monica Liliana Ojeda-Pardo, Diana Lorena Camelo-Prieto, Luís Andrés Téllez Tinjaca, Jorge Enrique Correa-Bautista, and Robinson Ramírez-Vélez. "Test-retest Reliability Of A Field-based Physical Fitness Assessment for Children and Adolescents Aged 9-17 Years." Medicine \& Science in Sports \& Exercise 48 (2016): 95-96.

[42] Tsigilis, Nikolaos, Helen Douda, and Sawas P. Tokmakidis. "Test-Retest Reliability Of The Eurofit Test Battery Administered To University Students." Perceptual and Motor Skills 95.3f (2002): 1295-300.

[43] Fjortoft, I., A. V. Pedersen, H. Sigmundsson, and B. Vereijken. "Measuring Physical Fitness in Children Who Are 5 to 12 Years Old With a Test Battery That Is Functional and Easy to Administer." Physical Therapy 91.7 (2011): 1087-095.

[44] Tokmakidis, Savvas P., Athanasios Kasambalis, and Antonios D. Christodoulos. "Fitness Levels of Greek Primary Schoolchildren in Relationship to Overweight and Obesity." European Journal of Pediatrics 165.12 (2006): 867-74.

[45] Manios, Yannis, Nikos Yiannakouris, Constantina Papoutsakis, George Moschonis, Faidon Magkos, Katerina Skenderi, and Antonis Zampelas. "Behavioral and Physiological Indices Related to BMI in a Cohort of Primary Schoolchildren in Greece." American Journal of Human Biology 16.6 (2004): 639-47.

[46] Magkos, F., Y. Manios, G. Christakis, and A. G. Kafatos. "Secular Trends in Cardiovascular Risk Factors among School-aged Boys from Crete, Greece, 1982-2002." European Journal of Clinical Nutrition 59.1 (2004): 1-7.

[47] Krassas GE, Tzotzas T, Tsametis C, Konstantinidis T. "Prevalence and Trends in Overweight and Obesity among Children and Adolescents in Thessaloniki, Greece." Journal of Pediatric Endocrinology \& Metabolism 14 Suppl 5 (2001): 1319-1326.

[48] Malina, Robert M., Gaston P. Beunen, Albrecht L. Claessens, Johan Lefevre, Bart Vanden Eynde, Roland Renson, Bart Vanreusel, and Jan Simons. "Fatness and Physical Fitness of Girls 7 to 17 Years." Obesity Research 3.3 (1995): 221-31.

[49] Okely, Anthony D., Michael L. Booth, and Tien Chey. "Relationships between Body Composition and Fundamental Movement Skills among Children and Adolescents." Research Quarterly for Exercise and Sport 75.3 (2004): 238-47.

[50] Grund, A., B. Dilba, K. Forberger, H. Krause, M. Siewers, H. Rieckert, and M. J. Müller. "Relationships between Physical Activity, Physical Fitness, Muscle Strength and Nutritional State in 5- to 11-year-old Children." European Journal of Applied Physiology 82.5-6 (2000): 425-38.

[51] Chatrath, R., R. Shenoy, M. Serratto, and D.g. Thoele. "Physical Fitness of Urban American Children." Pediatric Cardiology 23.6 (2002): 608-12.

[52] Gray, Amy, and Chery Smith. "Fitness, Dietary Intake, and Body Mass Index in Urban Native American Youth." Journal of the American Dietetic Association 103.9 (2003): 1187-191.

[53] Norman, A.C. Drinkard B, McDuffie JR, Ghorbani S, Yanoff LB, Yanovski JA. "Influence of Excess Adiposity on Exercise Fitness and Performance in Overweight Children and Adolescents." Pediatrics 115.6 (2005): 690-696.

[54] Ara, I., G. Vicente-Rodríguez, J. Jimenez-Ramirez, C. Dorado, J. A. Serrano-Sanchez, and J. A L Calbet. "Regular Participation in Sports Is Associated with Enhanced Physical Fitness and Lower Fat Mass in Prepubertal Boys." International Journal of Obesity 28.12 (2004): 1585-593.

[55] Guerra S, Ribeiro JC, Costa R, Duarte J, Mota J. "Relationship between cardiorespiratory fitness, body composition and blood pressure in school children". J Sports Med Phys Fitness 2002; 42: 207-213.

[56] Pongprapai S, Mo-suwan L, Leelasamran W. "Physical fitness of obese school children in Hat Yai southern Thailand". Southeast Asian J Trop Med Public Health 1994; 25: 354-360.

[57] Bettiol, H., R. J. Rona, and S. Chinn. "Variation in Physical Fitness between Ethnic Groups in Nine Year Olds." International Journal of Epidemiology 28.2 (1999): 281-86.

[58] Deforche, Benedicte, Johan Lefevre, Ilse De Bourdeaudhuij, Andrew P. Hills, William Duquet, and Jacques Bouckaert. "Physical Fitness and Physical Activity in Obese and Nonobese Flemish Youth." Obesity Research 11.3 (2003): 434-41.

[59] Dencker, M., O. Thorsson, M.k. Karlsson, C. Lindén, S. Eiberg, P. Wollmer, and L.b. Andersen. "Daily Physical Activity Related to Body Fat in Children Aged 8-11 Years." The Journal of Pediatrics 149.1 (2006): 38-42.

[60] Carrel, Aaron L., R. Randall Clark, Susan E. Peterson, Blaise A. Nemeth, Jude Sullivan, and David B. Allen. "Improvement of Fitness, Body Composition, and Insulin Sensitivity in Overweight Children in a School-Based Exercise Program." Archives of Pediatrics \& Adolescent Medicine 159.10 (2005): 963.

[61] Mitchell, Jonathan A., Calum Mattocks, Andy R. Ness, Sam D. Leary, Russell R. Pate, Marsha Dowda, Steven N. Blair, and Chris Riddoch. "Sedentary Behavior and Obesity in a Large Cohort of Children." Obesity 17.8 (2009): 1596-602.

[62] Gordonlarsen, P., M. Nelson, and B. Popkin. "Longitudinal Physical Activity and Sedentary Behavior TrendsAdolescence to Adulthood." American Journal of Preventive Medicine 27.4 (2004): 277-83.

[63] Katzmarzyk, Peter T., Jacques Gagnon, Arthur S. Leon, James S. Skinner, Jack H. Wilmore, D. C. Rao, and Claude Bouchard. "Fitness, Fatness, and Estimated Coronary Heart Disease Risk: The HERITAGE Family Study." Medicine and Science in Sports and Exercise (2001): 585-90.

[64] Johnson, M. S., R. Figueroa-Colon, S. L. Herd, D. A. Fields, M. Sun, G. R. Hunter, and M. I. Goran. "Aerobic Fitness, Not Energy Expenditure, Influences Subsequent Increase in Adiposity in Black and White Children." Pediatrics 106.4 (2000): E50.

[65] Astrup, Arne. "Macronutrient Balances and Obesity: The Role of Diet and Physical Activity." Public Health Nutrition 2.3a (1999): 341-347.

[66] Pollock, Michael L., Glenn A. Gaesser, Janus D. Butcher, Jean-Pierre Desprs, Rod K. Dishman, Barry A. Franklin, and Carol Ewing Garber. "ACSM Position Stand: The Recommended Quantity and Quality of Exercise for Developing and Maintaining Cardiorespiratory and Muscular Fitness, and Flexibility in Healthy Adults." Medicine \& Science in Sports \& Exercise 30.6 (1998): 975-91.

[67] Bovet, Pascal, Robert Auguste, and Hillary Burdette. "Strong Inverse Association between Physical Fitness and Overweight in Adolescents: A Large School-based Survey." International Journal of Behavioral Nutrition and Physical Activity 4.1 (2007): 24.

[68] Kaplowitz PB, Slora EJ, Wasserman RC, Pedlow SE, Herman- Giddens ME. Earlier onset of puberty in girls: relation to increased body mass and race. Pediatrics. 2001; 108:347-53.

[69] Beunen G, Thomis M. Muscular strength development in children and adolescents. Pediatr Exerc Sci. 2000;12:174-97.

[70] Al-Hazzaa HM. "Prevalence and trends in obesity among school boys in Central Saudi Arabia between 1988 and 2005." Saudi Med J 2007; 28:1569-74.

[71] Armstrong, Neil, and Joanne Welsman. "Essay: Physiology of the Child Athlete." The Lancet 366 (2005): $44-45$.

[72] Neinstein, L. S. "Adolescent Self-assessment of Sexual Maturation: Reassessment and Evaluation in a Mixed Ethnic Urban Population." Clinical Pediatrics 21.8 (1982): 482-84. 